Books, videos, CD-ROMs, DVDs and any other relevant items submitted for a review in the $B D J$ should be addressed to: Kate Maynard, Assistant Editor, British Dental Journal, NPG, 4-6 Crinan Street, London N1 9XW
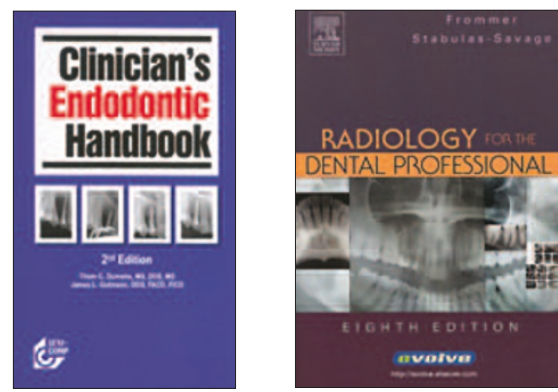

\section{Clinician's endodontic handbook (second edition)}

\author{
T. C. Dumsha, J. L. Gutmann \\ USA: Lexi-Comp \\ price $\$ 34.95$, pp 275 \\ ISBN 1591950864
}

This handbook presents endodontics in a nutshell. It is not meant to be a substitute for the many textbooks that are available, but to be something that can be kept to hand for the busy clinician.

The authors are the well known collaborators of the excellent Problem solving in endodontics. With that in mind the handbook has been written not only from a good theoretical base, but also has a wealth of clinical information.

The format is similar to the conventional textbooks with 21 chapters covering the whole subject. Each chapter is clearly laid out with the information presented in a series of bullet points, making it very easy to scan the information quickly. In amongst the pages of text are 'Clinical Notes' which appear like 'Post-Its' and contain highly practical tips. These notes are invaluable as they have anticipated likely pitfalls for the clinician of lesser experience. At the end of each chapter there is a section on Frequently Asked Questions.

The clinical chapters abound with useful practical information from root curvatures described in the chapter on anatomy - to the correct way to use apex locators. The chapter on radiographic interpretation has a very useful list of radiolucent and radiopaque lesions and then goes on to describe each lesion. The authors are completely up to date in the rapidly changing field of endodontics, as demonstrated in the section that discusses advantages and disadvantages of digital radiography.

So who is the handbook aimed at? Primarily it is aimed at the busy clinician who needs to get to the important information quickly. It would make excellent revision notes for the undergraduate and postgraduate student alike. Similarly teachers of endodontics could benefit greatly from the clear layout of each subject. With the authors' 50 years of experience, even the seasoned specialist may just pick up one or two useful pieces of information.

It is a little surprising that the handbook contains no illustrations except those on the front cover. This was clearly a conscious decision by the authors and their skilful descriptions do to some extent obviate the need for visual images. However images can sometimes be a more effective tool of communication than the written word. Having said that, this handbook will be greatly beneficial to all dentists wishing to tread through the minefield of endodontics.

\section{A. Druttman}

\section{Radiology for the dental professional (eighth edition)}

\section{F. Stabulas-Savage \\ UK: Elsevier \\ price $\mathrm{€37.99,} \mathrm{pp} 566$ \\ ISBN 0323030718}

This book was first published in 1974, previously titled Radiology for dental auxiliaries. The authors indicate that the aim of the book, as with previous versions, is to "apply basic principles to clinical practice'. The earlier editions were aimed at those professionals complementary to dentistry rather than at dental students or the dental practitioner. The new edition has an additional 101 pages compared to the seventh edition in order to try and widen its appeal. There are 25 chapters, an appendix and glossary of terms.

Over three quarters of the book is devoted to radiography, dealing with dental imaging including: radiation physics, biological hazards, radiation protection, processing, quality assurance and radiographic techniques both intraoral and extra-oral. These chapters are well written, amply illustrated with clear diagrams and radiographic images, which are mostly of acceptable quality.

It is unfortunate that the authors have continued to use the old radiation dose units of rads and rems, although SI units are described. While the book states that rectangular collimation is the single most effective factor is dose reduction, a number of the images illustrating intraoral radiographic technique show a set with a round cone, so it is unclear whether rectangular collimation is in fact being used. The section on selection criteria is brief and does not cover panoramic radiographs. In addition, the chapter on legislation applies to the USA situation and does not cover the regulations as applied to the United Kingdom.

Although the book has been enlarged, the chapters on interpretation are still too brief to provide the reader with much information other than a simple overview of conditions that affect the teeth and jaws, which limits its appeal for dental students and practitioners. For example, tumours and non-odontogenic cysts are covered in 10 lines and three illustrations.

So in summary, the authors have updated and expanded the amount of information over previous editions but not enough to cover the amount of detail required for a dental undergraduate course in the United Kingdom. 
Books, videos, cd-roms, dvds and any other relavent items submitted for a review in the bdj should be addressed to:

Mike Grace, Editor, British Dental Journal, 64 Wimpole Street WIG 8YS

\section{Paediatric dentistry (third edition)}

\author{
F. Stabulas-Savage \\ UK: Oxford University Press \\ price $€ 39.95$, pp 443
}

ISBN 9780198565833

The third edition of Paediatric dentistry is yet another improvement on the previous editions. This 433 page book is not only well written, but clearly laid out, and is an excellent text for easy reference both for the dental practitioner and the dental student. The 17 chapters are authored by 20 respected experts in the field of paediatric dentistry. Each chapter is subdivided into several concise sections. There are superb illustrations throughout which are relevant to the text, and all photographs are of a high standard. Two of the most appealing elements of the book are the 'Key points' feature which is highlighted in blue in relation to each topic, and the 'Summary page' at the end of each chapter. There is also advice on further reading in relation to each topic should the reader require more in-depth information.

The book starts off with a general overview of craniofacial growth and development that also entails dental development and eruption dates. This is then followed by a description of the psychology of child development, which is an important factor in treatment planning and for achieving successful treatment outcomes in young children.

The chapter on history taking, examination and diagnosis is followed by a chapter on pain management skills. This provides a sound basis for the succeeding chapters on treatment of dental caries in primary dentition, young permanent dentition and finally advanced restorative techniques in teenagers.

The book then continues with accounts of periodontal disease, dental trauma, oral pathology, dental anomalies and disability in children. The chapter on traumatic injuries to the
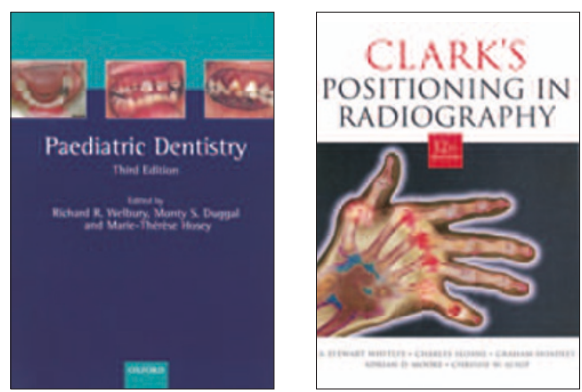

teeth is to the point and the authors have done a good job covering such a huge topic in a book of this size. However, the chapter on oral pathology and oral surgery was slightly disappointing. The oral pathology section was too brief with insufficient information on some of the more commonly occurring conditions such as herpetic infections. Many of the pictures were related to some of the rarer conditions in children. The oral surgery section contained long paragraphs of text, especially in relation to dental extraction, with hardly any illustrations - which could have been helpful in explaining patient and instrument positioning.

In conclusion, this book is probably the best available complete text on paediatric dentistry. I would absolutely recommend it to any clinician who wishes to improve their standards of paediatric dental care.

N. Attari

\section{Clark's positioning in radiography (twelfth edition)}

\author{
A. S. Whitley, C. Sloane, G. Hoadley, A. D. Moore, \\ C. W. Alsop \\ UK: Hodder Arnold \\ price $€ 75.00$, pp 517 \\ ISBN 0340763906
}

For 66 years students of radiography and radiology have relied on 'Kitty Clark' as the source book for advice and scholarship on radiographic positioning. The new edition represents a further step forward with hundreds of new positioning photographs, brand new explanatory line diagrams, and a clearly defined and easyto-follow structure. There are new sections on digital imaging and PACS. The basic principles of radiography and digital imaging are covered in the first chapter.
Specialists in dental imaging wrote chapter 10 , which deals concisely with dental radiography in 50 pages.

Following a general overview of dental radiography there is specific instruction on bitewing, periapical, and occlusal radiography, sections on lateral oblique projections, panoramic tomography and cephalometry. Each of these is clear, consistent and well illustrated with radiographs, diagrams, anatomical images and photographs showing ideal positioning. Many sections also contain examples of poor positioning, detailing what to look for and how positioning may be improved.

A small section in chapter 16 deals with forensic imaging in dentistry.

The rest of the body is covered in 13 chapters - each of similar high quality. The section on skull radiography is particularly welcome, as too many radiographers and radiologists have given up on plain film imaging in favour of CT.

This book is for those seeking either an introduction and/or a reference manual on radiographic positioning. It can be strongly recommended. Those with a specific focused interest in dental radiography may well move fairly rapidly on to a more detailed text, suggesting this volume should be on the workbench and in the library and classroom, rather than purchased by individuals.

\section{G. Cherryman}

